Departments of Surgery and Radiology, Royal

Postgraduate Medical

School, Hammersmith

Hospital, London

W12 0HS

G Williams, FRCs, consultant urologist

$R$ Jager, MD, senior registrar

J McLoughlin, FRCs, registrar

L Machan, FRCP, senior registrar

K Gill, FRCSI, registrar

R Asopa, FRCSED, registrar

A Adam, FRCR, radiologist

Medinvent SA, Lausanne,

Switzerland

A El Din MD, consultant

radiologist

Correspondence to:

Mr Williams.

BrMed f 1989;298:1429

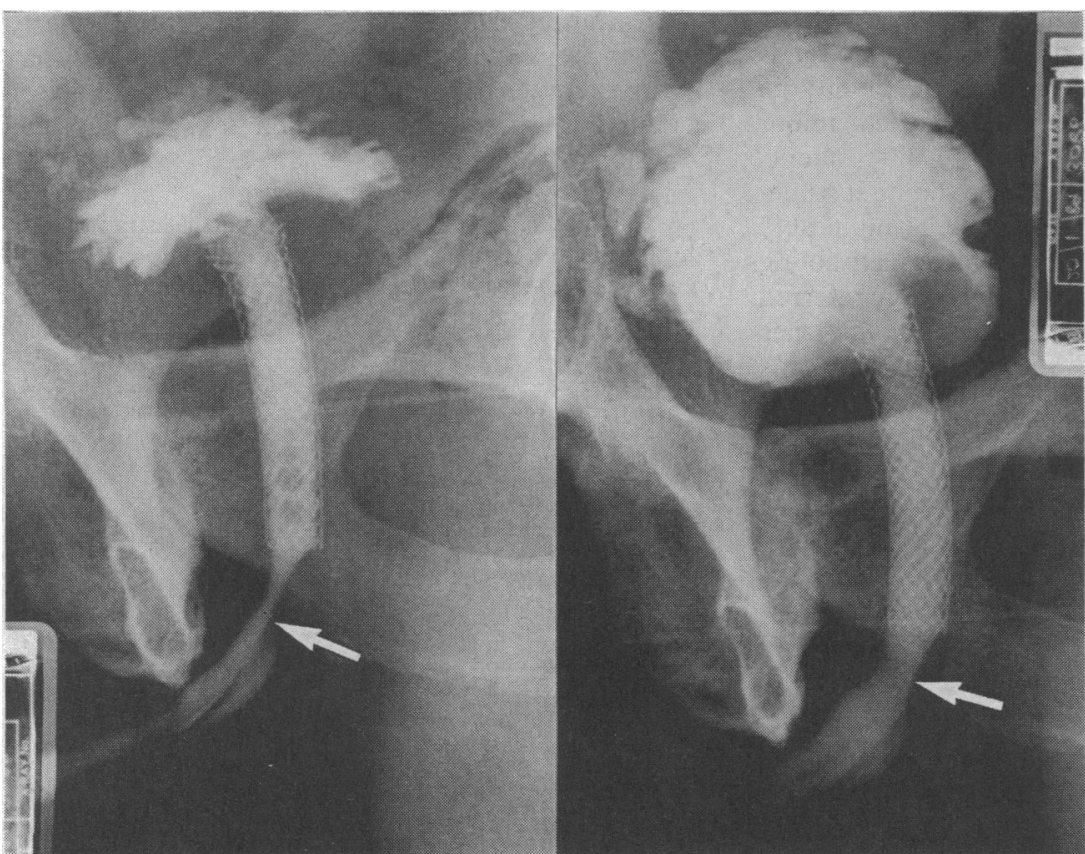

Retrograde urethrograms showing stent within prostatic urethra (left) and during voiding (right). Arrows indicate external sphincter

\section{Use of stents for treating obstruction of urinary outflow in patients unfit for surgery}

\author{
G Williams, R Jager, J McLoughlin, A El Din, \\ L Machan, K Gill, R Asopa, A Adam
}

Transurethral resection is the most widely accepted treatment for obstruction of urinary outflow. The associated morbidity and mortality have led to a search for less invasive treatments. Expandable tubular stents of stainless steel mesh have been used successfully in patients with recurrent urethral strictures. ${ }^{1}$ We assessed the safety and efficacy of these stents inserted into the prostatic urethra under topical anaesthesia in a group of patients considered to be unsuitable for surgery.

\section{Patients, methods, and results}

Nine patients aged between 70 and 84 with permanent indwelling catheters were treated. They had presented previously with obstruction of urinary outflow and were considered unsuitable for surgery. In the radiology department retrograde urethrography was performed to locate the external sphincter. With $2 \%$ lignocaine gel as the surface anaesthetic the end of the delivery device of a $14 \mathrm{~mm}$ diameter system (Wallstent, Medinvent) was pushed $1-2 \mathrm{~cm}$ past the neck of the bladder and the outer sheath withdrawn, leaving the stent lying within the prostatic urethra close to the external sphincter. A 14 French gauge catheter was introduced into the bladder through the stent over the guidewire. The catheter was removed 24 hours later and the position of the stent checked.

All nine patients voided spontaneously after removal of the urethral catheter. Peak urinary flow rates ranged between 10 and $22 \mathrm{ml} / \mathrm{s}$. No residual urine was detected in any patient on ultrasonography. One patient had mild stress incontinence for 12 days after the procedure but then became fully continent. After four months only two patients had developed a urinary infection, and both infections were asymptomatic.

\section{Comment}

We believe that we are the first to describe the use of prostatic stents to relieve obstruction of urinary outflow. These stents, which were originally designed for intravascular use,${ }^{2}$ have many features that make them ideal for use in the prostatic urethra: they are made from stainless steel mesh woven into a self expanding tube that can be restrained and inserted into a small bore delivery system and yet attain a calibre that allows good urinary flow (figure); they are elastic and strong enough to resist the closing pressure of the prostatic urethra; their pliability allows them to sit comfortably without appreciable distortion; the pores in the mesh allow the epithelium to cover the stent; and they do not prevent future endoscopy of the bladder.

Figures quoted for mortality related to prostatic surgery range from 1.6 to $6.4 \%$ in selected high risk groups and highlight the need for alternative forms of treatment. ${ }^{3}$ Insertion of stents is carried out easily in the radiology department under topical anaesthesia and does not require admission to hospital, although long term follow up is essential. At present we cannot advocate using stents to treat men with symptoms of obstruction of urinary outflow, but we hope that they may offer elderly and infirm patients an alternative to prostatic surgery.

1 Milroy EJG, Chapple CR, Cooper JE, et al. A new treatment for urethra strictures. Lancet 1988;: 1424-7.

2 Palmaz JC, Windler SA, Garcia F, Tio FO, Sibbit RR, Reuter SR. Atherosclerotic rabbit aortas: expandable intraluminal grafting. Radiology 1986;160:723-6.

3 Melchior J, Valk WL, Foret JD, Mebust WK. Transurethral prostatectomy in the azotemic patient. $\mathcal{F}$ Urol 1974;112:643-6.

(Accepted 16 March 1989)
Peterborough Health

Authority, Peterborough PE1 ILN

J K Anand, FFCM, district medical director

Ivy Court, CERTED (FAE), specialist teacher

Correspondence to: $\mathrm{Dr}$ Anand.

BrMed F 1989;298:1429-30

\section{Hearing loss leading to impaired ability to communicate in residents of homes for the elderly}

\section{J K Anand, Ivy Court}

An impaired ability to communicate leads to loss of independence, social isolation, irritation, and unhappiness. ${ }^{1}$ Sixty per cent of people aged over 70 have some degree of deafness. ${ }^{2}$ We tried to identify and ameliorate hearing loss that leads to an impaired ability to communicate in residents of homes for the elderly.
Subjects, methods, and results

Altogether 304 of the 316 residents of eight homes in Peterborough were assessed informally by IC, who is a specialist teacher experienced in the rehabilitation of adults with acquired hearing loss; three residents refused to be assessed, one did not understand English, and eight were away from the home. For the assessment IC and the resident sat facing each other about a metre apart in a quiet, well lit room. When necessary a personal amplifier was used to see whether communication improved. Audiometry was not used. Hearing aids were tested by switching them on, turning the volume to maximum, and holding them in a cupped hand; under these conditions a functioning aid should whistle. Non-functioning aids were tested for a flat battery and for twisted or blocked tubing; blockages 
caused by wax or condensation may be easily identified as the tubing is transparent.

Residents who were considered to have a hearing loss that affected them socially were followed up to see whether matters had improved after their hearing problems had been dealt with by IC or their general practitioners or at the audiology clinic.

The table shows the results. Half of the hearing aids already fitted were not functioning, nine because of flat batteries and 16 because of blockage by wax. Although

Findings in 304 residents whose hearing was assessed informally

\begin{tabular}{lc}
\hline Finding & No of residents \\
\hline Already fitted with an aid & 25 \\
Aid non-functioning & 25 \\
Aid functioning & 24 \\
Dementia not improved by amplification & 11 \\
Referred to audiology-hearing aid clinic for first time & 42 \\
Received hearing aid & 27 \\
Died before seen in clinic & 6 \\
Hearing improved after wax removal & 2 \\
Required no action & 4 \\
Admitted to hospital for reasons unconnected with ENT & 3 \\
Refused offer of referral to audiology department & 17 \\
Known to have hearing loss but uncooperative & 13 \\
Use of personal amplifier recommended & $7 \star$ \\
Found to have severely disabling tinnitus & 5 \\
Required wax removal & 79 \\
Referred to general practitioner but no action taken & 15 \\
Required no action & 132 \\
^ Patients too ill to travel to hospital. & \\
\hline
\end{tabular}

$\mathrm{ENT}=\mathrm{Ear}$, nose, and throat.

eight of the 24 residents fitted with functioning aids required no action, 10 needed a new mould or aid; the hearing aids of the remaining six needed minor attention such as new tubing. Of the 42 residents referred to an audiology clinic for the first time, five were confused and their mental state noticeably improved with the use of personal amplifiers. Disabling tinnitus was found in five residents, who were referred for counselling, relaxation training therapy, and trials with a masker (maskers look similar to hearing aids that fit behind the ear and introduce a band of sound into the ear which may be more tolerable than the person's tinnitus). In 11 patients the coexistence of deafness and dementia was probably coincidental. Overall we found that 154 of the 304 residents had a loss of hearing that affected them socially.

\section{Comment}

Fisch suggested that screening all elderly people makes sense only when care is available for all those who need it. 'We knew that we could cater for all the residents' hearing needs in this small scale study. In an audiometric study of 365 men and women aged 70 and over $60 \%$ were found to be deaf. ${ }^{3} \mathrm{We}$ found that about half of the residents $(51 \%)$ had a hearing loss that affected them socially. Nassar found that $23 \%$ of patients admitted to a geriatric ward needed to have wax removed ${ }^{4}$; our results were similar $(26 \%)$, and, in addition, 16 residents had hearing aids that were blocked with wax.

Our results in the five residents with confusion suggest that hearing should be assessed in confused elderly people. Ideally, an audiological technician should be available to carry out domiciliary work with elderly people, but resources are limited. We suggest that staff who care for elderly people should be trained to identify hearing difficulties and malfunctioning aids and to change batteries and blocked tubing. Every residential home should keep spare batteries as the life span of a battery may be as short as three days. As most people with hearing loss do not acknowledge their disability staff should be aware that confusion, irritableness, delayed responses, and changes in social behaviour may be signs of hearing loss that is affecting them socially.

The waiting list for our audiology clinic is short, about four weeks. Nevertheless, we recommend that the time between the initial assessment and audiological examination should be shortened to speed up the provision of hearing aids.

We thank Marks and Spencer for financial support, Dr Rhys Williams of the University of Cambridge and Dr B Tennison for helpful criticism, and Dr K. Sivageneshan for examining the patients referred to the audiology clinic.

1 Fisch L. Special senses-the aging auditory system. In: Brocklehurst JC, ed. Textbook of geriatric medicine and gerontology. Edinburgh: Churchill Living Textbook of geriatric

2 Corrado OJ. Hearing aids. Br Med f 1988;296:33-5.

2 Corrado OJ. Hearing aids. Br Med f 1988;296:33-5. living at home. $\mathrm{BrMed} \mathcal{f} 1980 ; 281: 903-5$.
lerbst KG, Humphrey C. Hearing impairm 4 Nassar A. Hearing impairment in the elderly. Br Med f 1980;281:1354

(Accepted 25 Fanuary 1989)
Medical Intensive Care

Unit, Department of

Medicine, King Edward

Memorial Hospital, Parel,

Bombay 400012, India

Dilip R Karnad, MD, lecturer in medicine

Avinash M Deo, MD, registrar in medicine

Nitin Apte, MD, lecturer in

medicine

Ashutosh S Lohe, MD,

registrar in medicine

Sunil Thatte, MD, registrar in medicine

G H Tilve, MD, professor of medicine

Correspondence to: Dr Karnad.

BrMed f 1989;298:1430-1

\section{Captopril for correcting diuretic induced hypotension in pulmonary oedema after scorpion sting}

\author{
Dilip R Karnad, Avinash M Deo, Nitin Apte, \\ Ashutosh S Lohe, Sunil Thatte, G H Tilve
}

Stings from the red scorpion (Buthus tamulus) are common in rural western India. ${ }^{\prime}$ The venom causes initial transient cholinergic stimulation followed by sustained adrenergic hyperactivity. ${ }^{2}$ Excess circulating catecholamines released from the adrenergic neurons and adrenal medulla cause myocardial damage similar to that seen in phaeochromocytoma. ${ }^{3}$ Hypoxia resulting from an increased myocardial requirement for oxygen is thought to be responsible. Myocardial damage and catecholamine induced increase in afterload cause pulmonary oedema after severe envenomation. ${ }^{3}$ Conventional treatment of cardiac failure after scorpion sting consists of digoxin and diuretics. We describe five patients with severe envenomation who presented with pulmonary oedema and developed a series of haemodynamic problems after parenteral diuretic treatment, for which they were given captopril.

\section{Patients and results}

All five patients were young (12-25 years) previously healthy residents of rural western India who were admitted to the medical intensive care unit four to 12 hours after envenomation. The figure summarises their clinical course and their response to therapeutic interventions. All patients initially had pulmonary oedema with a normal blood pressure, but, while respiratory distress and rales decreased after intravenous frusemide administration, hypotension and peripheral circulatory collapse occurred one to four hours later. Central venous pressures were low, and attempts to correct these with crystalloid infusion worsened the pulmonary oedema. Inotropic drugs (dopamine and dobutamine) produced improvement in blood pressure and pulmonary oedema, but the reduced cardiac preload persisted.

The first patient continued to receive dopamine and 